\title{
Integrated Analytical Study for the Authentication of Five Russian Icons (XVI-XVII centuries)
}

\author{
IRINA CRINA ANCA SANDU, ${ }^{1 *}$ SUSANNA BRACCI, ${ }^{2}$ ION SANDU, ${ }^{3}$ AND MARIELLA LOBEFARO ${ }^{4}$ \\ ${ }^{1}$ REQUIMTE - Faculty of Sciences and Technology (FCT) of the NOVA University of Lisbon (UNL), Department of Conservation \\ and Restoration, Campus da Caparica, Quinta da Torre, 2829-516 Caparica, Portugal \\ ${ }^{2}$ Istituto per la Conservazione e la Valorizzazione dei Beni Culturali (ICVBC-CNR), Via Madonna del Piano, 50019 Sesto \\ Fiorentino (FI), Florence, Italy \\ 3"Al. I.Cuza" University of Iasi, Arheoinvest Platform - Laboratory for Scientific Investigation and Cultural Heritage \\ Conservation Iasi, Romania \\ ${ }^{4}$ Cultural Association "Icons - Researches and Knowledge," Via Oropa 57 - 13900, Biella, Italy
}

KEY WORDS $\quad$ authentication; icons; painting technique; state of conservation; OM; SEM-EDX; FTIR

\begin{abstract}
This article presents an integrated approach for the authentication of five Russian icons through the study of their paint materials (elemental composition and stratigraphic mapping), state of conservation and artistic technique. The results of the applied analytical protocol, involving optical and scanning electron microscopy coupled with energy-dispersive X-ray spectrometry and Fourier transformed infrared spectroscopy/microspectroscopy, led to the conclusion that the five icons belong to the same group and iconographic school (from Northern Russia) and date from the end of the 16 th century to the beginning of 17 th century. Because of massive overpainting, the icons "suffered" a change in iconographic style and significance, and restoration treatment brought to light the original painting and its attribution. Identification of the composition of the original chromatic palette used by the iconographer, the stratigraphic mapping and the conservation state of the painting materials, along with the features of the original artistic technique, furnished key elements for the icons' authentication. Here, we present the first experimental data concerning the identification of the authentication characteristics, being part of a large project that has as its final aim the evaluation of the effectiveness and effects of the cleaning agent on the paint layers. Microsc. Res. Tech. 72:755-765, 2009. @ @2009 Wiley-Liss, Inc.
\end{abstract}

\section{INTRODUCTION}

After the conquest of Constantinople by the Turks in 1453 , the art of the Icons testified to the continuation of Byzantine traditions in several countries: Greece, Bulgaria, Romania, Russia, Macedonia, Albania, Serbia, Croatia, etc. These religious works of art ensured the survival of "Byzantium after Byzantium" through the foundation of local schools, and contributed to the preservation of national identities of the aforementioned peoples, which shared a common faith and roots (Lobefaro, 2003; Popova et al., 2003; Sandu et al., 2005; Sendler, 2001; Taylor, 1979). Among them, Russia was one of the major producers of icons and the cities of Kiev, Novgorod, Moscow, Pskov, Palech, etc. became important iconographic centres, famous the world over.

The present research aimed to authenticate five Russian icons representing Saint Prophets, belonging to an Italian private collection. As usually happens with post-Byzantine icons, improvised "restorers" had introduced overpainting, puttying, and cleaning without taking into consideration the original materials and basic principles of conservation and restoration. Thus, the owner requested further restoration treatments, focused on the removal of the negative effects of these "mutilating" interventions, from a private laboratory in Northern Italy (Biella). The restoration work begun in June 2007, aimed to consolidate the paint layers and clean the icons, mainly by removing the overpaintings that were hiding the original iconography and chromatic palette.

The five icons were painted on one-piece coniferous wood panels of $\sim 68 \mathrm{~cm} \times 31.8 \mathrm{~cm}$, with gilded halos around the heads of each of the Saints. From a stylistic point of view, the icons were initially assigned to Northern Russia (Karelia?) and the period between the end of 16 th and beginning of 17 th centuries (Fig. 1). Signs of original drawing were visible in the red vest of the prophets Malachia and Samuel (Icons 2 and 3), in black color and with free-hand brushing.

Authenticating post-Byzantine and late icons is one of the trends of this collaboration, as it is a challenging and multidisciplinary activity, in which art history, iconography, chemistry, and material sciences bring their contribution to the establishment of parameters or characteristics useful for assessing the originality, uniqueness and/or authorship of the studied art-objects (Daniilia et al., 2008a,b; Domenech et al., 1996; Kouloumpi et al., 2007; Sandu et al., 2006a,b, 2007, 2008a,b).

\footnotetext{
*Correspondence to: Irina Crina Anca Sandu, REQUIMTE and Department of Conservation and Restoration, Faculty of Sciences and Technology (FCT), NOVA Conservation and Restoration, Faculty of Sciences and Techn
University of Lisbon (UNL), 2829-516 Caparica, Portugal. E-mail: irina.sandu@dq.fct.unl.pt

Received 27 November 2008; accepted in revised form 22 March 2009

Contract grant sponsor: CNCSIS (National Council of Scientific Research for Superior Education), Romania.

DOI 10.1002/jemt.20727

Published online 17 April 2009 in Wiley InterScience (www.interscience.wiley.com).
} 


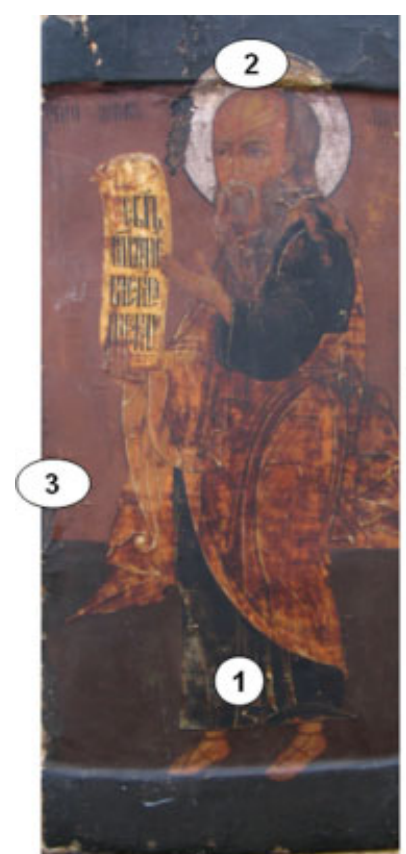

icon 1

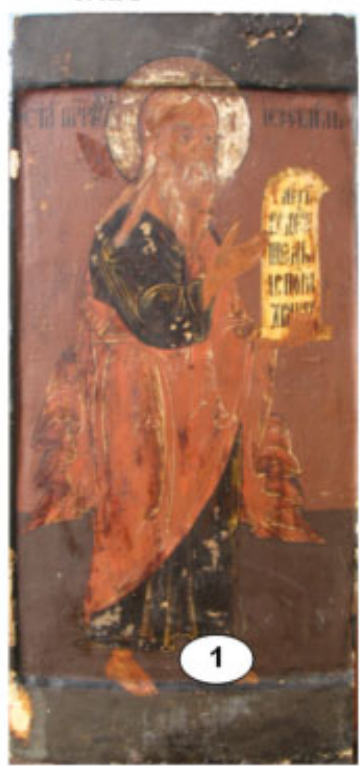

icon 4

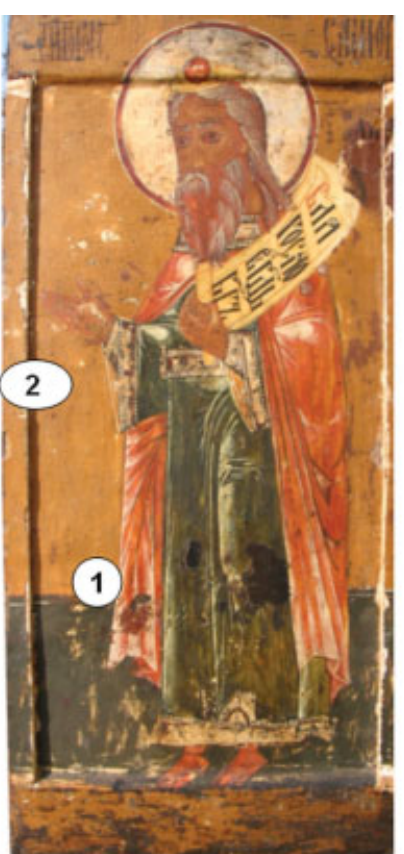

icon 2

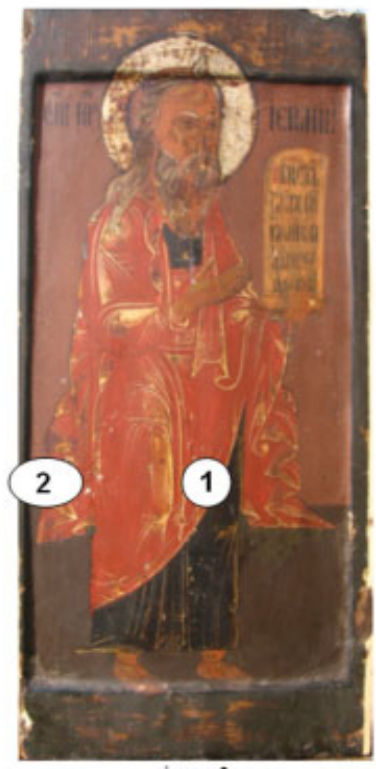

icon 5

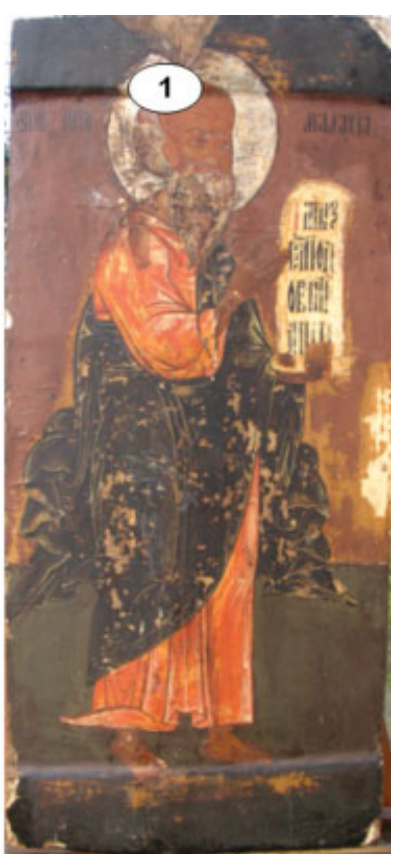

icon 3

Fig. 1. The five sampled icons.

The main objective of this work is to distinguish between the original materials and those added by subsequent overpainting interventions (Casellato et al., 1995; Ganitis et al., 2004). An integrated multimethod approach using microscopy and spectroscopy is proposed and tested for authenticating these religious paintings on wooden supports (Domenech et al., 1996; Schreiner et al., 2007; Sotiropoulou et al., 2008). Pigments, mineral charges, and metallic leaves were characterized using light microscopy (OM, UV-Vis), scanning electron microscopy coupled with energy-dispersion X-ray spectroscopy (SEM-EDX) and micro-FTIR, whereas the organic components of the paint layers (binders and varnishes) were identified by the specific fluorescence images using UV light microscopy and by Fourier transform infrared spectroscopy. By crossreferencing the results obtained from these three techniques, it was possible to make an accurate distinction between the original materials/layers of the paint in the five icons and the overpainting.

\section{MATERIALS AND METHODS Sampling and Analytical Protocol}

The nine samples of paint layers taken from the five icons (as it is shown in Table 1 and Fig. 1) covered the 
TABLE 1. Description of the sampled icons

\begin{tabular}{|c|c|c|c|}
\hline Icon no. & Title/dimensions & Description & No. of samples \\
\hline 1 & $\begin{array}{l}\text { S. Proph. Michea, } \\
68 \times 31.8 \times 3.6 \mathrm{~cm} \times \mathrm{cm} \times \mathrm{cm}\end{array}$ & $\begin{array}{l}\text { Tempera, gilding layer (mecca technique), on entire wooden panel } \\
\text { with frontal grooved background }\end{array}$ & 3 \\
\hline 2 & $\begin{array}{l}\text { S. Proph. Samuel, } \\
68 \times 31.5 \times 3.5 \mathrm{~cm} \times \mathrm{cm} \times \mathrm{cm}\end{array}$ & $\begin{array}{l}\text { Tempera, gilding layer (mecca technique) on entire wooden panel } \\
\text { with frontal grooved background (two overlapped icons) }\end{array}$ & 2 \\
\hline 3 & $\begin{array}{l}\text { S. Proph. Malachia, } \\
68 \times 32 \times 3.8 \mathrm{~cm} \times \mathrm{cm} \times \mathrm{cm}\end{array}$ & $\begin{array}{l}\text { Tempera gilding layer (mecca technique) on entire wooden panel with } \\
\text { two movable slats on the backside }\end{array}$ & 1 \\
\hline 4 & $\begin{array}{l}\text { S. Proph. Jezechiel, } \\
68 \times 31.8 \times 3.8 \mathrm{~cm} \times \mathrm{cm} \times \mathrm{cm}\end{array}$ & $\begin{array}{l}\text { Tempera gilding layer (mecca technique) on wooden panel with } \\
\text { frontal grooved background }\end{array}$ & 1 \\
\hline 5 & $\begin{array}{l}\text { S. Proph. Geremia, } \\
\quad 68 \times 31.8 \times 3.5 \mathrm{~cm} \times \mathrm{cm} \times \mathrm{cm}\end{array}$ & $\begin{array}{l}\text { Tempera gilding layer (mecca technique) on wooden panel with } \\
\text { frontal grooved background }\end{array}$ & 2 \\
\hline
\end{tabular}

TABLE 2. Taken samples and performed analyses

\begin{tabular}{|c|c|c|c|c|c|}
\hline $\begin{array}{l}\text { Icon } \\
\text { no. }\end{array}$ & $\begin{array}{l}\text { Samples } \\
\text { ID }\end{array}$ & Area of sampling & $\begin{array}{l}\text { MO (UV-Vis) } \\
\text { on cross-section }\end{array}$ & $\begin{array}{l}\text { SEM/EDX on } \\
\text { cross-section }\end{array}$ & $\begin{array}{l}\text { FTIR on } \\
\text { samples }\end{array}$ \\
\hline \multirow[t]{3}{*}{1} & 1S1 & $\begin{array}{l}\text { Green-brown fragment from the vest of the Prophet, with } \\
\text { original "olifa" (varnish) }\end{array}$ & - & - & $\mathrm{X}$ \\
\hline & $1 \mathrm{~S} 2$ & Gilding layer fragment from the halo of the Saint & $\mathrm{X}$ & $\mathrm{X}$ & - \\
\hline & $1 \mathrm{~S} 3$ & Red-brown fragment (overpainting) from the left border of the icon & $\mathrm{X}$ & $\mathrm{X}$ & $\mathrm{X}$ \\
\hline \multirow[t]{2}{*}{2} & $2 \mathrm{~S} 1$ & Red fragment from the vest with white original highlights & $\mathrm{X}$ & $\mathrm{X}$ & - \\
\hline & $2 \mathrm{~S} 2$ & $\begin{array}{l}\text { Yellow-ochra fragment from the left border, treated with a } \\
\text { cleaning agent }\end{array}$ & $\mathrm{X}$ & - & $\mathrm{X}$ \\
\hline 3 & $3 \mathrm{~S} 1$ & $\begin{array}{l}\text { Fragment of flesh from the Prophet's forehead with a small } \\
\text { area of overpainting }\end{array}$ & $\mathrm{X}$ & $\mathrm{X}$ & $\mathrm{X}$ \\
\hline 4 & $4 \mathrm{~S} 1$ & Dark green fragment from the vest with white highlights & $\mathrm{X}$ & $\mathrm{X}$ & $\mathrm{X}$ \\
\hline \multirow[t]{2}{*}{5} & $5 \mathrm{~S} 1$ & Red fragment from the vest & $\mathrm{X}$ & $\mathrm{X}$ & - \\
\hline & $5 \mathrm{~S} 2$ & $\begin{array}{l}\text { Brown fragment from the background, left border, area } \\
\text { of overpainting }\end{array}$ & $\mathrm{X}$ & $\mathrm{X}$ & $\mathrm{X}$ \\
\hline
\end{tabular}

entire chromatic palette and were selected with the aim of obtaining information regarding the pigments and painting technique, as well as for describing of the state of conservation of the paint in stratigraphic sequence. Table 1 summarizes the main data: titles, dimensions, short description, and number of samples taken from each icon.

With the help of a magnifying glass, the samples were taken with a scalpel from representative areas (fulfilling the condition of selective sampling of a polychrome artwork), taking into consideration lacunas, cracks, or abrasions that could facilitate sampling of the entire structure of the paint layers (Table 2). The samples are indexed as follows: the first number represents the icon's number, $S$ is abbreviation for Sample, and the last number is the sample's progressive number for each icon (e.g., 1S1, 1S2, etc). The weight of each sample varied between 0.4 and $1 \mathrm{mg}$.

After microscopic observation and photographic documentation, a microfragment was identified in each sample which was embedded in synthetic resin to obtain cross-sections representative of what had been observed. Part of the sample was preserved for spectroscopic analysis.

\section{Optical Microscopy (OM) on Cross-Section}

The cross-sections, obtained from fragments of the paint-layer samples, which were embedded in Polyester resin Mecaprex SS (Leica), were properly polished after the necessary curing time, and observed under a Nikon Eclipse E600 binocular microscope (4-40× magnification), with both visible and UV light, and then photographed with a Nikon DXM1200F digital camera.
The block of filters used for UV fluorescence was B$2 \mathrm{~A}$ type (excitation radiation at 330-380 $\mathrm{nm}-\mathrm{EX}$, observation at $420 \mathrm{~nm}-\mathrm{BA})$.

\section{SEM Microscopy Coupled with EDX Microanalysis}

For the morphological characterization of the samples embedded as cross-sections and for EDX microanalysis, a SEM, VEGA II LSH scanning electron microscope (TESCAN, Czech Republic) coupled with an EDX, QUANTAX QX2 detector (ROENTEC, Germany) was used, working at $<1 \times 10^{-3} \mathrm{~Pa}$ vacuum pressure, a $30.00 \mathrm{KV}$ voltage, varying the working distance between 11 and $20 \mathrm{~mm}$ (16.6 $\mathrm{mm}$ for EDX analysis) and the magnifying power between 78 and $1.000 \times$ in the resolution mode, with a scanning speed between 200 and $10 \mathrm{~ms}$ per pixel. The seven cross-sections analyzed by this method (as shown in the Table 2) were coated with a thin layer of graphite.

The qualitative and quantitative (for some cross-sections) microanalyses were done both on areas and spots (cross-bared points) on the analyzed samples.

\section{FTIR and Micro-FTIR Spectroscopy}

The FTIR analysis was done with a Perkin Elmer System 2000 spectrophotometer at 64 scans in the interval of $4000-500 \mathrm{~cm}^{-1}$, in transmission mode with a diamond cell.

For confirming the presence of a green $\mathrm{Cu}$-based pigment in the surface layers, two micro-FTIR analyses were preformed on two samples. A Nicolet Nexus spectrophotometer interfaced with a Continuum microscope with a MCT-A detector cooled by liquid nitrogen 
was used. The spatial resolution is $30 \mu \mathrm{m}$, the spectra being obtained with a resolution of $4 \mathrm{~cm}^{-1}$ and 128 scans, in absorbance mode, in an interval between 4000 and $600 \mathrm{~cm}^{-1}$, using a Thermo diamond anvil compression cell.

\section{RESULTS}

The microscopic analyses were useful for assessing the stratigraphic sequence and the morphological, chromatic, and compositional characteristics of the original paint layers versus the overpaintings and also for describing their conservation state and the extension of previous restorations. OM and SEM observation allowed comparison of the morphologic pattern of the ground layers and also the measurement of the thickness of the layers in the cross-sections. The fluorescence image of the various layers in the cross-sections observed under UV light, in some cases, indicated the presence of an oily varnish and helped also to distinguish between the original paint layer and any overpainting.

The FTIR and micro-FTIR spectroscopy correlated with EDX microanalysis allowed the identification of various mineral charges and pigments, and also the composition of the gilding layers of Icon 1 . With the help of SEM-EDX analysis, distribution maps of various elements of each layer in the analyzed cross-sections were also obtained.

\section{DISCUSSION \\ Painting Materials and Technique}

Table 3 summarizes the main pigments, mineral charges, and other components identified in the analyzed icons, for each layer of sample stratigraphy.

The ground (white preparation layers covering the wooden support) has a variable thickness between 0.2 and $0.4 \mathrm{~mm}$. It was applied over pieces of cloth that do not cover all the surface of the panels but only some areas that are more sensitive to dimensional variation, such as the upper and lower sides and the biggest knots in the wood, as showed by radiographic analysis. The thick preparation was generally applied in several layers, separated from one another in Icons 2, 3, and 4, clearly visible under microscopic observation (Fig. 2). The combined information of FTIR spectra and EDX microanalysis of the ground layers indicate the presence of dihydrated calcium sulfate (gypsum) as mineral charge, in many cases accompanied with aluminum-silicates as colored grains inside the matrix of gypsum crystals (Figs. 3 and 4). The grain size and morphology of the charge in various samples, observed at $1000 \times$ with the backscattered electron detector (BSE), indicates analogous composition and thus homogeneous methods of preparation of the gesso grounds in the five icons (Fig. 4).

The gypsum crystals have a relatively homogeneous round-shaped granulometry, with inclusions of various dimensions and colors, containing $\mathrm{Al}$ and $\mathrm{Si}$. The presence of these impurities (clay minerals based on $\mathrm{Al}$ and Si elements) corresponds to what is referred to in the literature as the use of white earths based on kaolinite in grounds and priming layers for post-Byzantine icons (Genestar and Pons, 2005; Hradil et al., 2003). The identification of gypsum (known as "levkas" in Russian language) in the preparation of all five icons confirmed the assessment in the literature concerning the traditional use of this charge in ancient icon painting (Daniilia et al., 2002; Lobefaro, 2003; Matteini and Moles, 1989; Sandu et al., 2006a,b).

Although the paint samples have a complex composition and the corresponding FTIR spectra display many peaks, in most of the samples the identification of constituent materials was possible. A certain differentiation was done during sampling, by dividing the fragments and selecting only small quantities of preparation or paint layer. In many cases, it was not possible to remove only the varnish from the surface paint layer and therefore in the same spectrum peaks belonging to the colored layer (binder and pigment) and to the varnish were identified. The same situation was verified for FTIR analysis of colored samples of paint in which residues of preparation were detected.

The pigments are mainly of mineral origin, the chromatic palette being limited to few pigments, such as: red and yellow earths (Ochras), Cu-based pigment (Verdigris), green earth and brown earth or umber, Caput Mortum. The basic lead carbonate was used both in mixtures with other pigments in the paint layer and as pure pigment (lead white, a typical pigment for post-Byzantine icon painting) for highlights on vests and flesh, as in Icon 2 (sample 2S1) and Icon 4 (sample 4S1) (Fig. 5).

In the green layer of sample $4 \mathrm{~S} 1$, the EDX analysis detected the presence of $\mathrm{Cu}$ together with $\mathrm{Si}, \mathrm{K}, \mathrm{Fe}, \mathrm{Al}$, and this can be an indication of a mixture of Copper pigment (Verdigris) and silicates (Green earth). In fact, the micro-FTIR and FTIR spectra (Fig. 6) of this green layer confirm the presence of $\mathrm{Cu}$ acetate (Verdigris) mixed with a small quantity of proteinaceous material, as the EDX microanalysis (Fig. 3) identified the presence of $\mathrm{Ca}$ together with $\mathrm{Cu}$. An ancient painting recipe mentioned by Sendler (2001) indicates the use of calcium caseinate (or better, the curdled milk) for the preparation of the green pigment known as Verdigris (caseinate as substitute of acetate is an hypothesis to be further verified with chromatographic analysis, although the absence of $P$ from the EDX spectrum would exclude the presence of casein-a phosphor-protein used as binder in ancient painting) (Sendler, 2001). The micro-FTIR spectrum of $4 \mathrm{~S} 1$ green layer is similar to the spectrum obtained for the same color of sample 1S1, and this confirms the use of the same pigment or mixture of pigments for the Icons 4 and 1 .

The binder present inside the ground is made of animal glue (proteinaceous material), confirmed by the FTIR spectra obtained for various samples of preparation layers (Fig. 6); identified by specific absorbance values at $1630-1680 \mathrm{~cm}^{-1}$ (amide band) and 1520-1560 $\mathrm{cm}^{-1}\left(\mathrm{NH}_{2}\right)$ in conjunction with the strong peaks attributed to methylenic groups at around 2929 and 2850 $\mathrm{cm}^{-1}$ in the relative FTIR spectra (Adrover, 2001).

The binder inside the original paint layers is the traditional emulsion made of egg yolk, as many of the acquired FTIR spectra contain the values: 2924, 2850 $\mathrm{cm}^{-1}$ for CHstr (proteins), $1731-1736 \mathrm{~cm}^{-1}$ for CO (triglycerides), $1650-1658 \mathrm{~cm}^{-1}$ (CO) and 1535-1541 $\mathrm{cm}^{-1}$ $\left(\mathrm{NH}_{2}\right)$ for Amides I and II (Adrover, 2001; Daniilia et al., 2002; Domenech et al., 1996). The use of egg yolk was a common practice in icon painting since the 14th 
TABLE 3. Results of the analyses for each layer of the samples [Color table can be viewed in the online issue, which is available at www.interscience.wiley.com.]

\begin{tabular}{cccc}
\hline Sample & $\begin{array}{c}\text { Surface color of } \\
\text { sample }\end{array}$ & $\begin{array}{c}\text { Color of layers in } \\
\text { cross-section }\end{array}$ & Mineral charge and pigments \\
\hline 1S1 & $\begin{array}{c}\text { Brown-green from } \\
\text { the vest of the } \\
\text { Saint }\end{array}$ & White (preparation) & $\begin{array}{c}\text { Grganic components } \\
\text { (binders, varnishes) }\end{array}$ \\
& & $\begin{array}{c}\text { Green-brown with } \\
\text { residues of varnish }\end{array}$ & $\begin{array}{c}\text { Gypsum, Verdigris, Silicates } \\
\text { (Green Earth?) (FTIR) }\end{array}$
\end{tabular}

Gilding area from the Saint's aureole

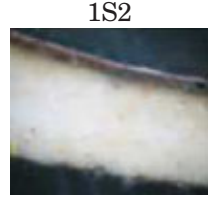

1S3

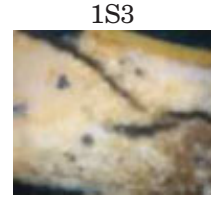

2S1

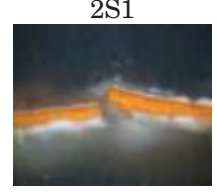

2S2

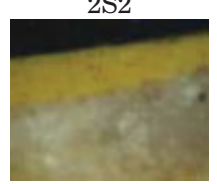

$3 \mathrm{~S} 1$

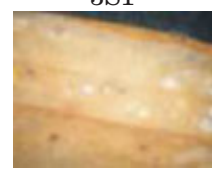

4S1

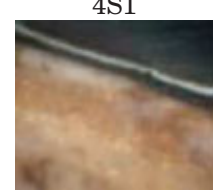

$5 \mathrm{~S} 1$

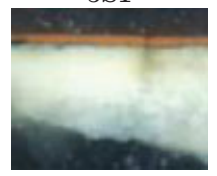

5S2

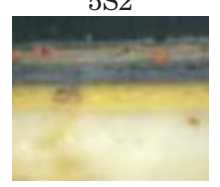

Brown-ochra from the background

Red-yellowish fragment from the vest of the saint

Ochre from the background

Brown-ochre from the forehead of the Saint

Green from the vest of the Saint

Red fragment from the vest,

repainting area

Brown fragment from the

background, repainting area
White (preparation)

Red

Silver

White (preparation)

Yellow

Red-brown

White (preparation) Yellow orange

White

White (preparation)

Yellow ochre

White (preparation)

Red-brown ochre

White (preparation)

Green

Brown and white (the white is a highlight on the garment)

White (preparation)

Red

White (preparation)

Yellow

Brown-bluish

Grey-bluish

Red-brown
Gypsum (FTIR, SEM-EDX)

Gypsum and red earths

(SEM-EDX)

Leaf of silver, several applications (SEM-EDX)

Gypsum with silicatic impurities (FTIR, SEM-EDX)

Yellow ochra/earths (SEM-EDX) Red earths (FTIR, SEM-EDX)

Gypsum (SEM-EDX)

Mixture of lead white and yellow-red ochra/earths (SEM-EDX)

Lead white with kaolin impurities (SEM-EDX)

Gypsum (FTIR)

Ochre/yellow earths (FTIR)

Gypsum with earthy impurities (FTIR, SEM-EDX)

Red ochras/earths and litharge, as dessicant agent in the varnish layer (FTIR, SEM-EDX)

Gypsum with silicatic impurities (FTIR, SEM-EDX)

Green earth and copper pigment (Verdigris) (FTIR, SEM-EDX)

Brown earths, lead white (FTIR, SEM-EDX)

Gypsum with silicatic impurities (SEM-EDX)

Red earth/ochra and silicates (SEM-EDX)

Gypsum (FTIR, SEM-EDX)

Yellow ochra/earths (SEM-EDX)

Lead pigment-Litharge in the olifa layers (FTIR, SEM-EDX)

Brown earths (mixtures of pigments) and Litharge (FTIR, SEM-EDX)

Brown earth/caput mortum, litharge (FTIR, SEM-EDX)
Animal glue as binder (FTIR)

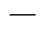

Animal glue as binder residues of an oily emulsion? (FTIR)

Egg emulsion as binder (FTIR)

Animal glue as binder (FTIR)

Egg emulsion as binder (FTIR)

Animal glue as binder (FTIR)

Egg emulsion as binder, oily varnish (olifa) (FTIR)

Animal glue as binder (FTIR)

Egg emulsion as binder (FTIR)

Oily varnish (olifa) (FTIR)

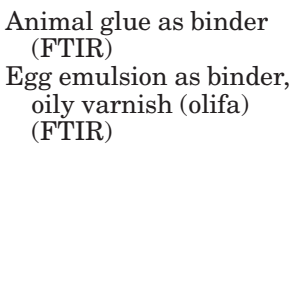




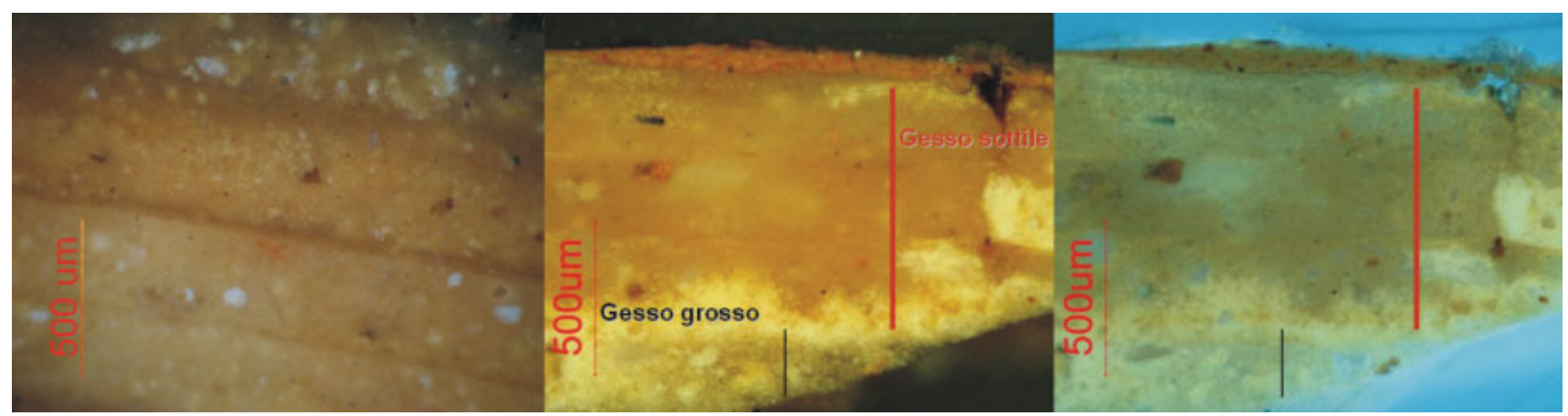

Fig. 2. Cross-sections showing the ground in sample 3S1 made of various layers of gesso, observed in visible and UV light $(\times 100)$. [Color figure can be viewed in the online issue, which is available at www.interscience.wiley.com.]

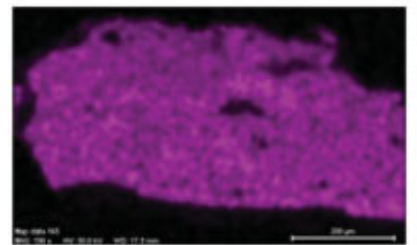

$\mathrm{Ca}$

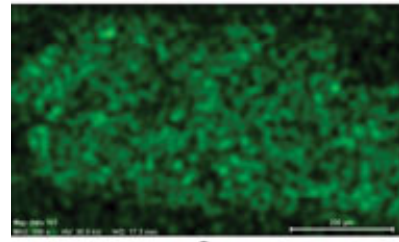

O

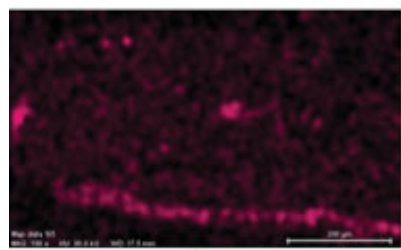

K

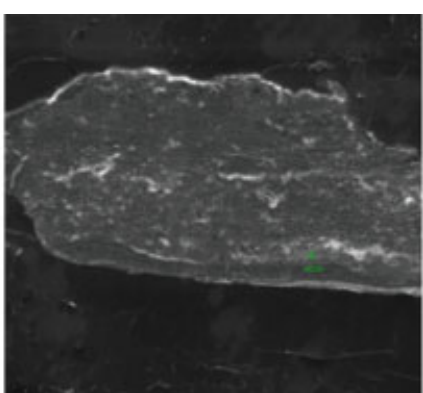

200X, BSE

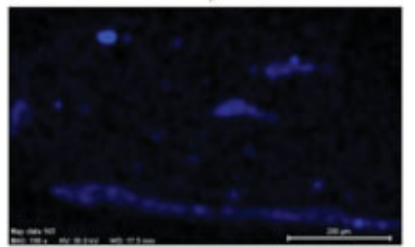

Si

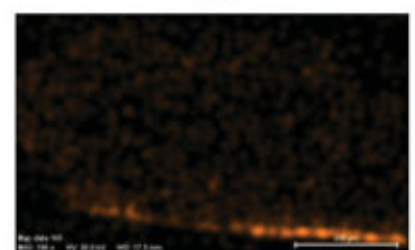

$\mathrm{Pb}$

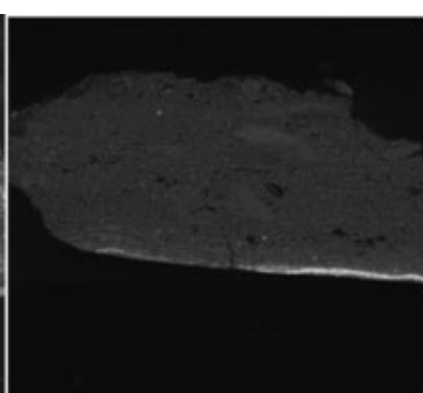

$200 \times$ SE

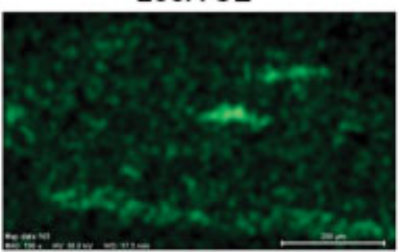

Al

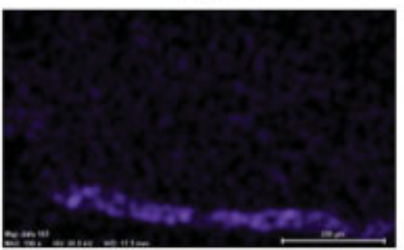

$\mathrm{Cu}$

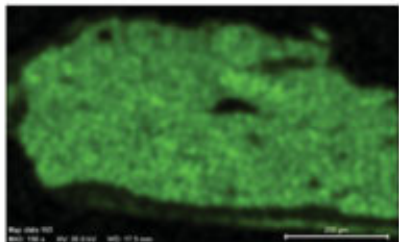

S

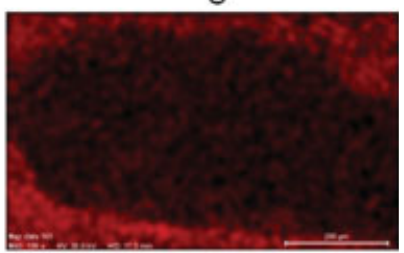

C

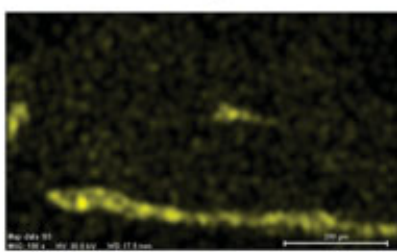

$\mathrm{Fe}$

Fig. 3. Element mapping in sample 4S1 analyzed by SEM-EDX. [Color figure can be viewed in the online issue, which is available at www.interscience.wiley.com.]

to 15th centuries, whereas the mixed technique ("tempera grassa": egg and linseed oil as binder) was introduced to the Russian icon after the era of Peter the Great. Considering that the spectrum of aged yolk is very similar to the one of linseed oil, it is difficult in this case to assess with extreme precision whether a yolk or an oily egg emulsion was used as the binder (Daniilia et al., 2008a,b; Ganitis et al., 2004; Sandu et al., 2008b). In this case, if small amounts of oil are present it could also be due to the penetration of "olifa" during repeated varnishing (all five icons were subject to several applications of olifa, the traditional varnish of Russian icons, made from boiled linseed oil added with a desiccant pigment or charge).
The carbonyl peaks (usually attributed to fatty fraction, esters, of binders or varnishes, Adrover, 2001) occur at $1710-1714 \mathrm{~cm}^{-1}$ for overpainting layers in samples 1S3 and 5S2 (Fig. 7), at $1733-1730 \mathrm{~cm}^{-1}$ for brown layer in sample $1 \mathrm{~S} 1$ and at $1736-1734 \mathrm{~cm}^{-1}$ in sample $4 \mathrm{~S} 1$. These values of absorbance can be indicative of the presence of oily medium/varnish (olifa) in overpainted areas (samples 1S3 and 5S2) and of egg yolk in the other samples.

The varnish is not present in all the samples as it was removed during previous cleaning interventions (mainly from Icon 2), but in a few cases (samples 1S1, 1S3, 4S1, 5S2) the FTIR spectra contain peak values (2920-2928, 2848-2855, 1710-1720 $\left.\mathrm{cm}^{-1}\right)$ which are 


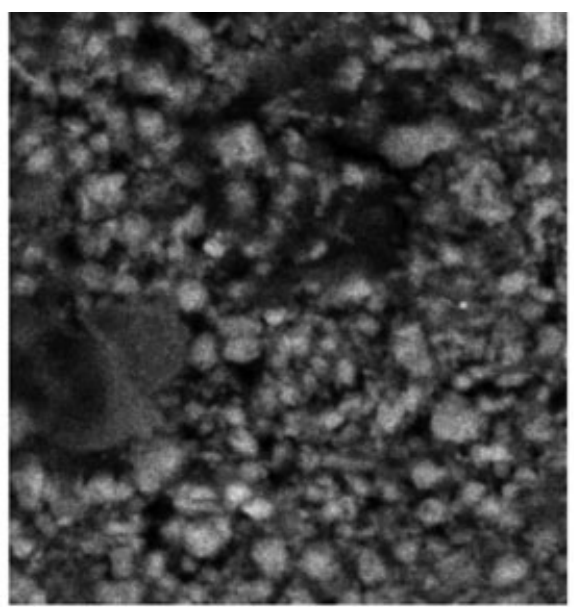

a

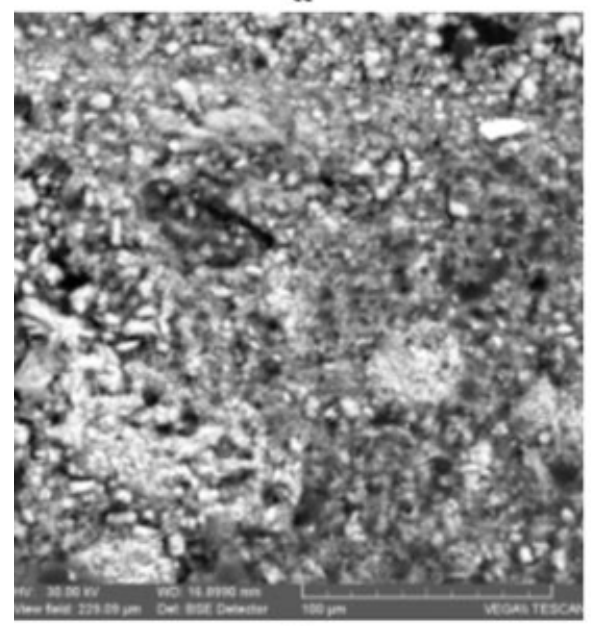

C

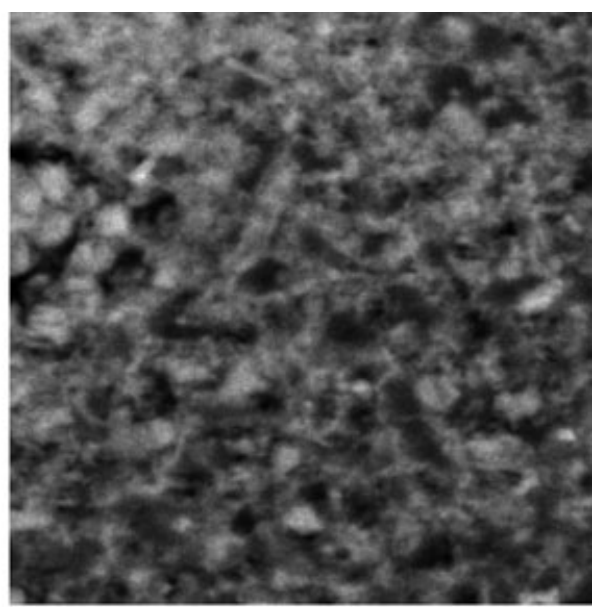

b

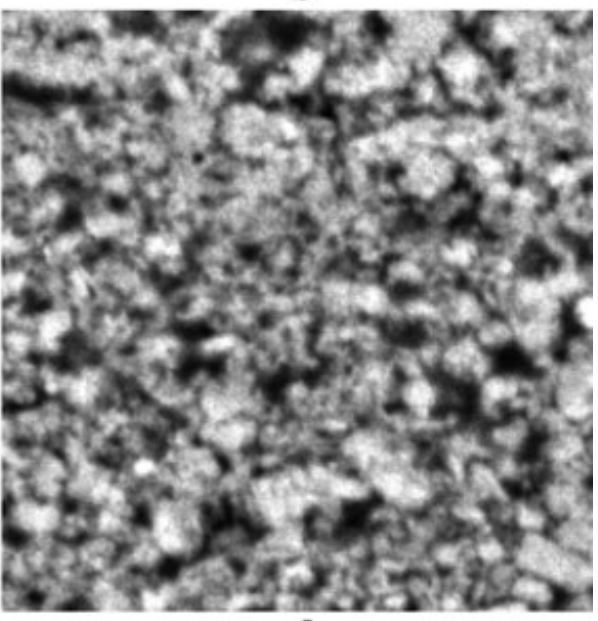

d

Fig. 4. Comparison between detailed SEM photos (backscattered electrons) at $1000 \times$ of the studied ground layer for icons: (a) Icon 1, (b) Icon 2, (c) Icon 3, and (d) Icon 5.
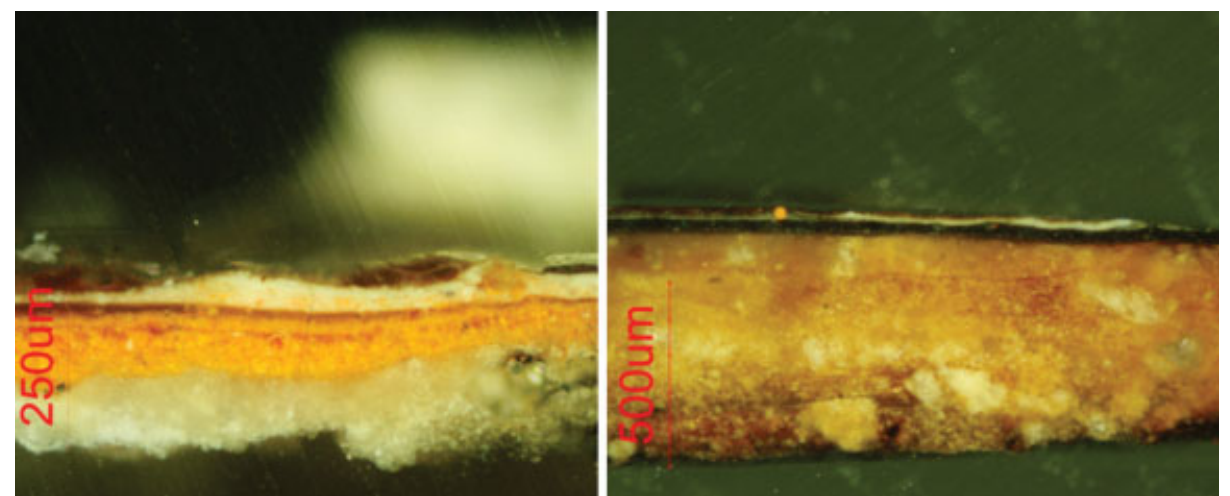

Fig. 5. Cross-section under visible light of samples: $2 \mathrm{~S} 1, \times 100$ and $4 \mathrm{~S} 1, \times 50$ (red and green areas with highlights). [Color figure can be viewed in the online issue, which is available at www.interscience. wiley.com.]

characteristic of an aged oily varnish, and could be attributed to the traditional olifa (Daniilia et al., 2002; Ganitis et al., 2004). In layers corresponding to this oily varnish (samples $1 \mathrm{~S} 3,2 \mathrm{~S} 1,5 \mathrm{~S} 2) \mathrm{Pb}$ was detected, and its presence can be an indication of the use of a lead pigment as a dessicant for olifa (Litharge, $\mathrm{PbO}$ ), as the traditional technique required (Lobefaro, 2003; Sandu et al., 2005; Sendler, 2001). 
The painting technique seems to be the canonical one: egg tempera, paint structure made of several layers, varying in complexity from a simple stratigra-

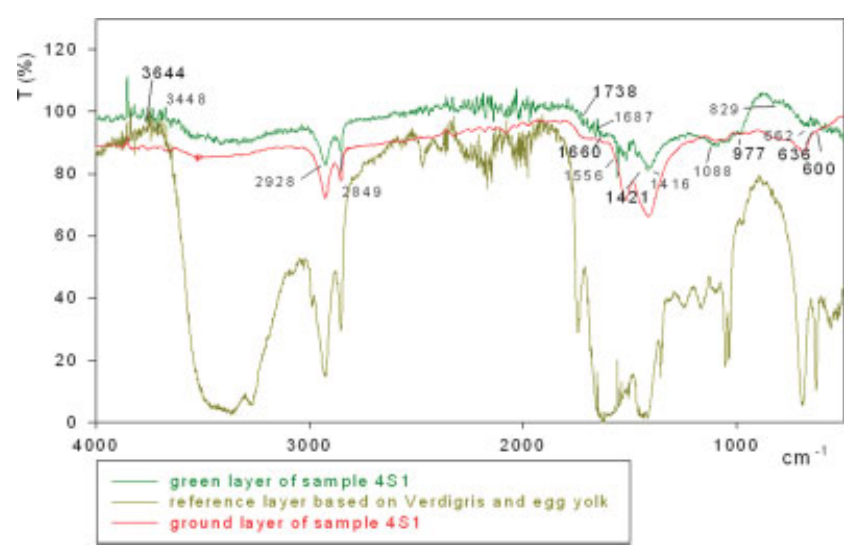

Fig. 6. FTIR spectra of sample 4S1, green layer based on Verdigris and fragment of ground. [Color figure can be viewed in the online issue, which is available at www.interscience.wiley.com.]

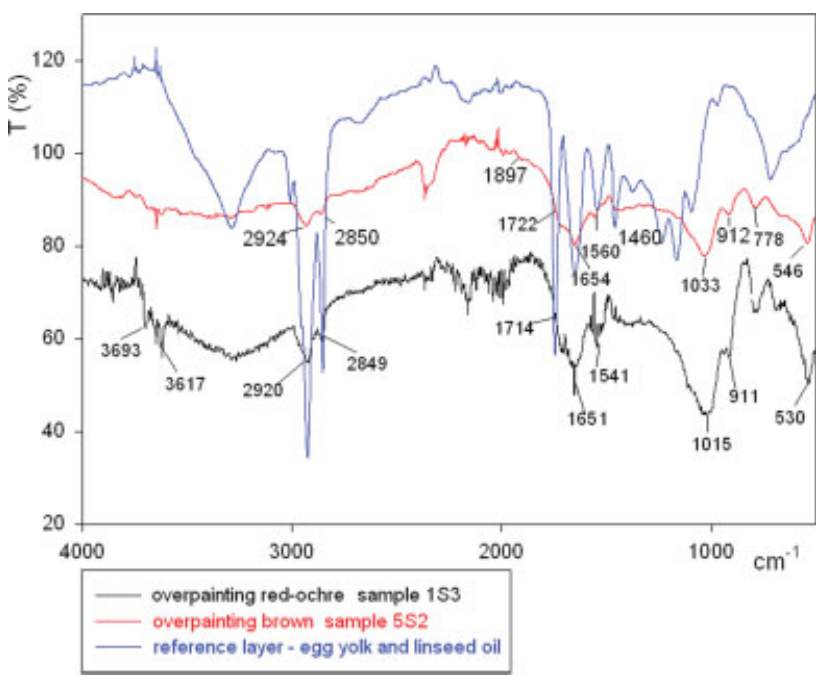

Fig. 7. FTIR spectra of overpaintings in samples $1 \mathrm{~S} 3$ and $5 \mathrm{~S} 2$ [Color figure can be viewed in the online issue, which is available at www.interscience.wiley.com.] phy of one layer of paint to more complex ones (Figs. 2, 5 , and 8), in which more than four color layers can be present (particularly in the case of Icon 5, sample 5S2, where several layers of overpainting over the yellow one were added). The ground has a multilayer structure, characterized by the presence of three layers of "gesso sottile" (thin gesso) applied over a thick gypsum priming ("gesso grosso"), as shown by sample 3S1 (Fig. 2).

The halos of the saints were done with "mecca gilding" with various applications of silver leaf, coated with final protective layers of a resinous varnish. For Icon 1, the silver leaf identified in sample 1S2 was applied with "mecca" technique (Fig. 9), with several applications of thin leaf, interlayered with varnish, and silicate-based layers of overpainting (probably a red earth) (Daniilia et al., 2002; Lobefaro, 2003; Sandu et al., 2005, 2006b).

The icons' original yellow background was almost entirely overpainted and this intervention was probably the cause for the change in the chromatic appearance of the paint due to darkening of the original varnish (olifa), whereas for flesh the overpaintings could be attributed to a stylistic change, known to have been developed during the second half of 17th century but which spread to the most far provinces during the 18th century (Popova et al., 2003).

This yellow background is made of an ochre-based pigment (found in samples 1S3, 2S2, 5S2) over which other applications of a red-brown color were introduced in Icons 1, 3, and 4. The FTIR and the EDX spectra, together with the relative SEM mapping for this layer in sample 5 $\mathrm{S} 2$, indicate the presence of residues of gesso (O, 54.63\%; C, 22.35\%; Ca, 0.69\%) and Si (10.88\%), Al $(5.34 \%), \mathrm{Fe}(5.23 \%), \mathrm{K}(0.87 \%)$ : the pigment used in this case was a yellow Earth-Ochra (Fig. 10). The FTIR spectrum of sample 2S2 indicates for the same yellowcolored layer, the presence of silicatic components, identified by a broad band between 800 and $1150 \mathrm{~cm}^{-1}$ (Genestar and Pons, 2005).

\section{State of Conservation}

The cracks that are clearly visible in the images obtained with OM and SEM (as for the sample 3S1 in Fig. 11) indicate an ageing process of all the constituent materials of the paint.

By simple observation, the most evident paint alteration is the darkening and yellowing of the olifa

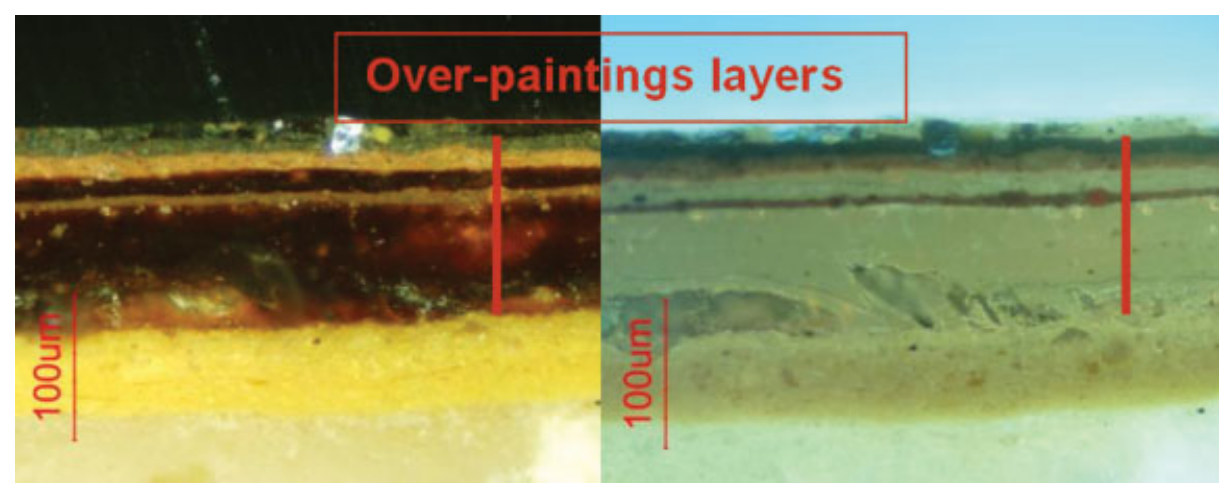

Fig. 8. Cross-section of sample 5S2 showing the overpainted area under UV-Vis light, $\times 200$. [Color figure can be viewed in the online issue, which is available at www.interscience.wiley.com.] 

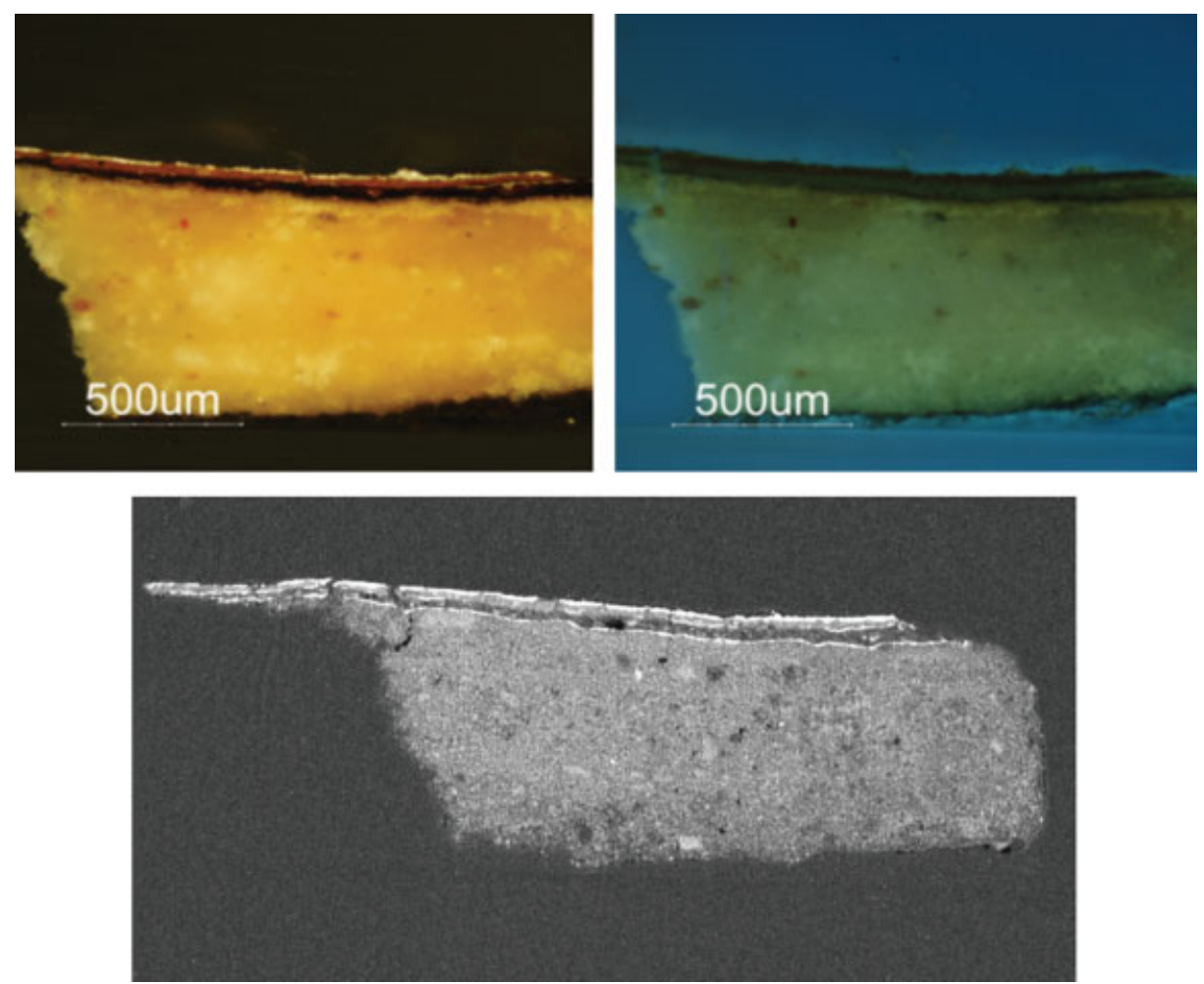

Fig. 9. "Mecca" gilding of the halo of the Saint, sample 1S2, detail of cross-section observed under UV-Vis at $\times 200$ and SEM image BSE at $\times 88$ of the same cross-section. [Color figure can be viewed in the online issue, which is available at www.interscience.wiley.com.]
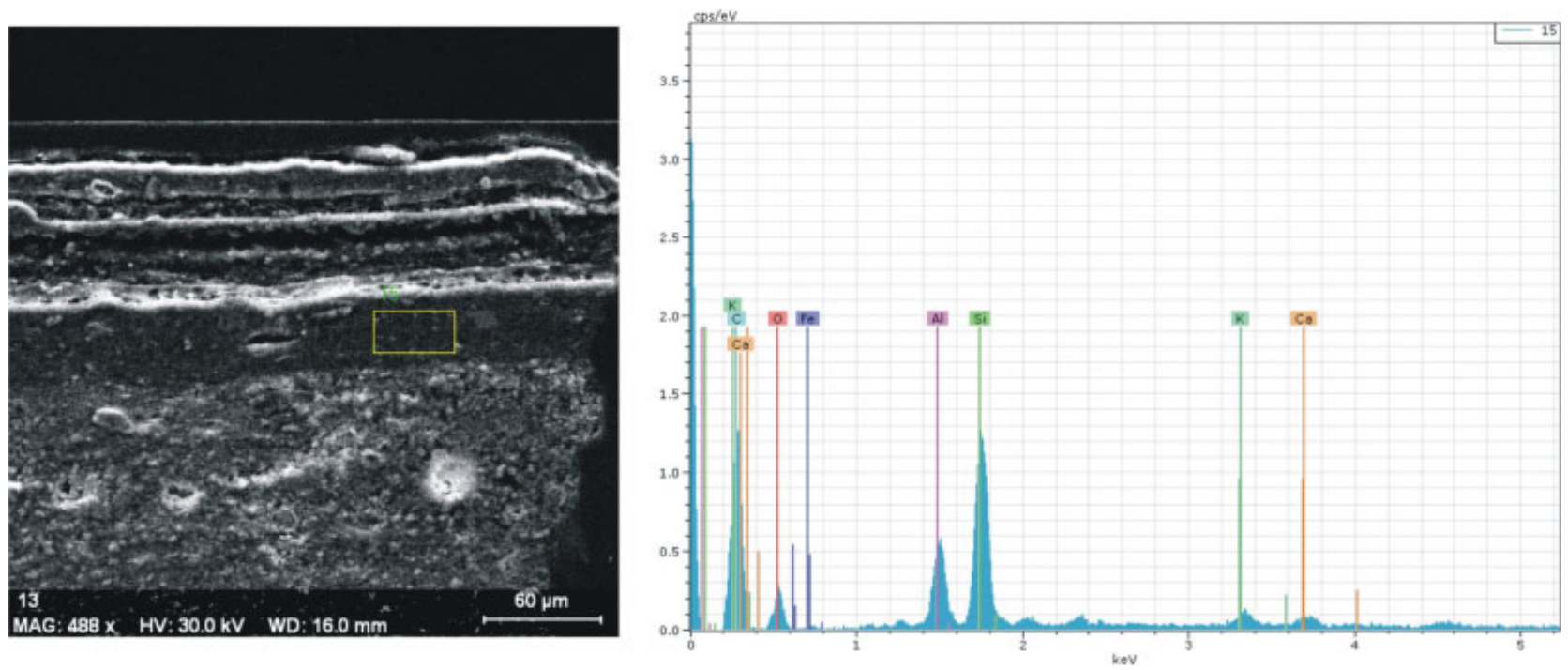

Fig. 10. Cross-section of sample 5S2 observed at SEM $(\times 488$, se $)$ and the relative EDX spectrum for the yellow-ochre layer, marked with an yellow square on the SEM image. [Color figure can be viewed in the online issue, which is available at www.interscience.wiley.com.]

(protective layer), that in several cases was covered by extensive overpainting (in Icons 1,4 , and 5 ). The overpaintings need to be removed by cleaning from Icons 1 , 3,4 , and 5 , whereas Icon 2 should be consolidated.
Important losses of paint layers and lacunas are localized on the external borders of the icons (Fig. 1). The samples taken from these areas showed the effect of the aforementioned interventions on the appearance 

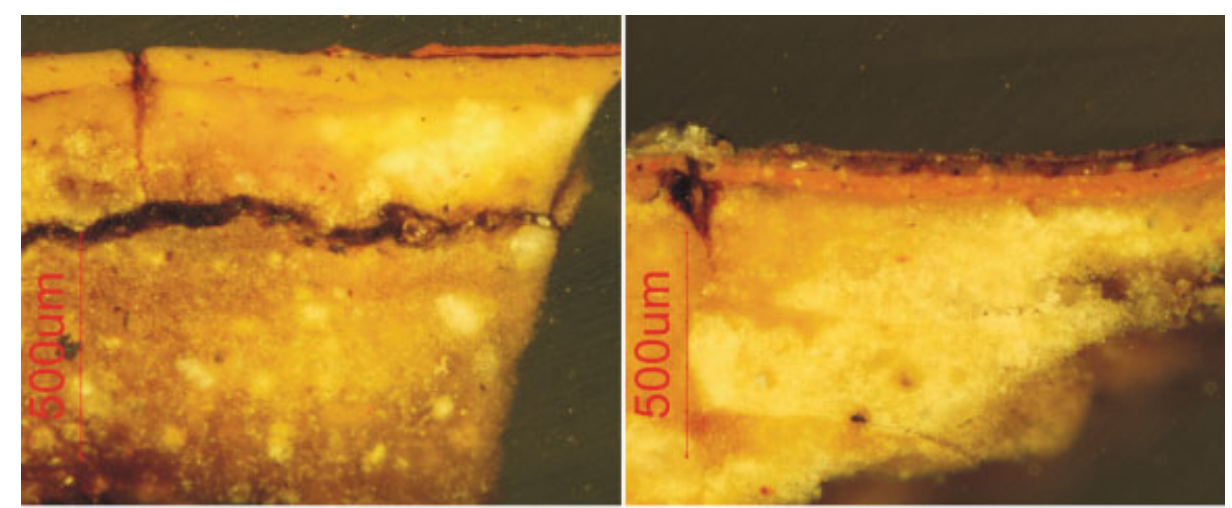

a
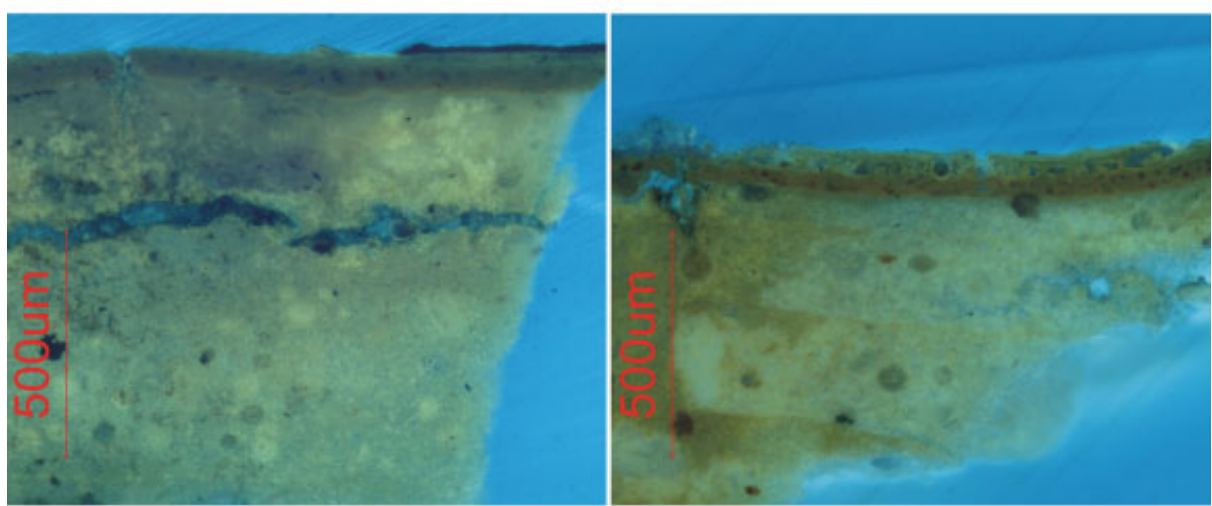

b

Fig. 11. Cross-sections of samples 3S1 and 1S3 observed with the light microscope under visible (a) and UV (b) light, $\times 50$ - age cracking in the paint stratification and surface residues of an oily varnish. [Color figure can be viewed in the online issue, which is available at www.interscience.wiley.com.]

and color of the preparation layers. For example, in sample 1S3, the preparation has transversal fissures, penetrated by a brown material, representing a solvent that dissolved the soot allowing it to penetrate the cracks (Fig. 11).

The intense yellow fluorescence of the two central applications of preparation in sample 3S1, together with the clearly delimited layers of "gesso sottile," indicate the ground's technique of application: first the "gesso grosso" with a warm layer of glue over and then three thick layers of gesso sottile separated after a previous polishing of the surface by layers of animal glue (Figs. 2 and 11).

In the samples $1 \mathrm{~S} 2-3,2 \mathrm{~S} 2,3 \mathrm{~S} 1,4 \mathrm{~S} 1$, and $5 \mathrm{~S} 2$, which were taken from areas of the background or gilded halos, the various forms of degradation (cracks, lacunas) allowed the penetration of the warm glue or of dissolved "olifa" from upper layers, during cleaning.

\section{Previous Interventions of Overpainting and Cleaning}

In the past, the five icons were overpainted in several areas (as can be seen in samples from Icons 1, 1S3; $3,3 \mathrm{~S} 1$; and $5,5 \mathrm{~S} 2$ ) and were also subject to severe interventions of cleaning (complete or partial removal of "olifa" with an aggressive cleaning agent in the case of Icons 2, 3, 4 and 5). The only icon that gave a fair indication of the original colors of the chromatic palette was Icon 2, which preserved signs of an aggressive and disturbing cleaning and puttying intervention.

The overpainting layers at the level of the background were observed using the optical microscope. In the cross-sections of samples taken from Icons 1 and 5, the original layers were distinguished from the added ones by their sequence, morphology and UV fluorescence (such as in samples 1S3, Fig. 11 and 5S2, Fig. 8). As Figure 1 illustrates, this intervention respected the central image, and was done mainly on the borders, over the original layer of yellow ochre. This layer proved to be the original background color of all the icons, as shown in Figures 5, 8, and 11.

\section{CONCLUSIONS}

The reported analytical study led to the following conclusions:

- the five icons were made with a similar technique and comparable materials (according to the postByzantine icon tradition), in the style of Northern Russian schools of iconography, at the end of the 16th and beginning of the 17th centuries: several paint layers with egg yolk emulsion applied on grounds made of "gesso" and animal glue;

- the ground has a homogeneous granulometry, with relatively round-shaped grains and aluminum-silicatic inclusions of various dimensions and colors, 
made up of clay minerals (white earths) and oxides; the application of "gesso" layers corresponds to the traditional sequence: "gesso grosso" as a first application and three layers of "gesso sottile," with thin layers of animal glue in between them;

- the different appearance of the preparation layers in correspondence with the cracks and lacunas extending from the paint layer inside the "gesso" could be a result of several applications of warm oily varnish (a practice quite often encountered in the case of Russian icons) or of interventions of cleaning that resulted in the penetration of dissolved "olifa" inside the ground;

- the colored layers are applied continuously and the boundaries between one layer and another are clearly distinguishable, meaning that the traditional technique of application was respected: each layer was applied after the previous one had dried;

- the pigments are mainly of mineral origin, the chromatic palette being limited to a small number of pigments, such as: red and yellow Earths (Ochras), green and brown earth or umber/Caput Mortum, copper pigment (Verdigris) mixed with green earths, lead white;

- the pigments were mixed with a medium made of egg yolk and the varnish identified in few samples of surface paint is the traditional "olifa," made of siccative linseed oil and additives such as $\mathrm{Pb}$ oxides (known as litharge, $\mathrm{PbO}$ );

- each represented Saint has a gilded halo around the head, probably a later intervention of gilding with "a mecca" technique as the SEM-EDX analysis identified the presence of Silver leaf in several application with intermediate layer of organic medium;

- the microscopic analyses revealed the presence of cracks that overcross the entire structure of the pictorial layers (Icons 1, 2, 3, and 5), as a result of the ageing process that occurred over time;

- the intervention of overpainting (brownish layer) on the grooved border was confirmed for Icons 1 and 5 (samples 1S1, 1S2, 1S3, and 5S2), whereas the absence of the varnish in paint samples $1 \mathrm{~S} 3,2 \mathrm{~S} 2,5 \mathrm{~S} 1$ indicates a previous cleaning of Icons 1,2 , and 5 .

The multimethod approach, combining microscopic and spectroscopic techniques, was confirmed to be extremely useful for establishing the authenticity of the analyzed icons through the identification of the constitutive materials and their methods of application. In addition, the results confirmed that a careful study of materials and artistic technique/technology in a work of art can lead to better planning and execution of the restoration, by discriminating between the original and added materials, and offering a better diagnosis of their original state of conservation. The obtained information will also be the basis for the study and assessment of the effectiveness of the cleaning process to be reported in a future article.

\section{ACKNOWLEDGMENTS}

Special thanks to A.V. Sandu from the Romanian Inventors Forum of Iasi, who assisted in the SEM-EDX analyses of samples and to C. Lugnani from RCL Padova for radiographic analysis.

\section{REFERENCES}

Adrover IG. 2001. Applicazioni della spettrofotometria IR allo studio dei beni culturali. Il Prato, Padova: Colana I Talenti.

Casellato U, Guerriero P, Tamburini S, Vigato PA, Soroldoni L. 1995 XRD, FTIR con microscopio, SEM-EDS su sezioni stratigrafiche, tre tecniche integrate per una corretta indagine scientifica e caratterizzazione dei materiali pittorici. In: Proceedings of the Ist International Congress on Science and Technology for the safeguard of Cultural Heritage in the Mediterranean Basin, Vol. 1. Siracusa: Catania. p. 735

Domenech Carbo MT, Bosch Reig F, Gimeno Adelantado JV, Periz Martinez V. 1996. Fourier transform infrared spectroscopy and the analytical study of works of art for purposes of diagnosis and conservation. Anal Chim Acta 330:207-215.

Daniilia S, Burgio L, Bikiaris D, Gavala P, Clarck RJH, Chryssoulakis Y. 2002. An extensive non-destructive and micro-spectroscopic study of two post-Byzantine over-painted icons of the 16th century. J Raman Spectrosc 33:807-814.

Daniilia S, Minopoulou E, Andrikopoulos KS, Tsakalof A, Bairachtari K. 2008a. From Byzantine to post-Byzantine art: The painting technique of St Stephen's wall paintings at Meteora, Greece. J Archaeol Sci 35:2474-2485.

Daniilia S, Minopoulou E, Demosthenous FrD, Karagiannis G. 2008b. A comparative study of wall paintings at the Cypriot monastery of Christ Antiphonitis: One artist or two? J Archaeol Sci 35:16951707.

Ganitis V, Pavlidou E, Zorba F, Paraskevopoulos KM, Bikiaris D. 2004. A post-Byzantine icon of St. Nicholas painted on leather support. Microanalysis and characterization of technique. J Cult Herit 5:349-360

Genestar C, Pons C. 2005. Earth pigments in painting: Characterization and differentiation by means of FTIR spectroscopy and SEMEDS microanalysis. Anal Bioanal Chem 382:269-274.

Hradil D, Grygar T, Hradilovà J, Bezdicka P. 2003. Clay and iron oxide pigments in the history of painting. Appl Clay Sci 22:223236.

Kouloumpi E, Vandenabeele P, Lawson G, Pavlidis V, Moens L. 2007. Analysis of post-Byzantine icons from the Church of the Assumption in Cephalonia, Ionian Islands, Greece: A multi-method approach. Anal Chim Acta 598:169-179.

Lobefaro M. 2003. La tecnica esecutiva di base delle icone antiche, in Lo Stato dell'arte: Conservazione e restauro, confronto di esperienze. Atti del Primo Congresso Nazionale dell'IGIIC: Torino.

Matteini M, Moles A. 1989. Tecniche della pittura antica: Le preparazioni del supporto. Kermes, Arte e Tecnica del Restauro 4. Firenze: Nardini.

Popova O, Smirnova A, Cortesi P. 2003. Icone, Guida completa al riconoscimento delle icone dal VI secolo a oggi, Guide Cultura, Milano: Mondadori Electa.

Sandu ICA, Sandu I, Luca C. 2005.Modern aspects concerning the conservation of cultural heritage, Vol. 2. Authentication and determination of conservation state of old paintings. Iasi: Performantica.

Sandu I, Sandu ICA, Vasilache V, Geaman ML. 2006a. Modern aspects concerning the conservation of cultural heritage. Vol. 4. Determination of conservation state and easel painting restoration. Iasi: Performantica.

Sandu ICA, Bracci S, Sandu I. 2006b. Instrumental analyses used in the authentication of old paintings. I. Comparison between two icons of XIXth century. Rev Chim (Bucharest) 57:796-803.

Sandu I, Luca C, Sandu ICA, Vasilache V. 2007. Authentication of ancient easel-paintings through materials identification from the polychrome layers. I. Gas-chromatography analysis. Rev ChimBucharest 58:621-634.

Sandu ICA, Luca C, Sandu I, Vasilache V, Hayashi M. 2008a. Authentication of ancient easel-paintings through materials identification from the polychrome layers. II. Analysis by means of the FTIR Spectrophotometry. Rev Chim (Bucharest) 59:384-387.

Sandu ICA, Luca C, Sandu I, Vasilache V, Hayashi M. 2008b. Authentication of ancient easel-paintings through materials identification from the polychrome layers. III. Cross-section analysis and staining test. Rev Chim (Bucharest) 59:855-866.

Schreiner M, Melcher M, Uhlir K. 2007. Scanning electron microscopy and energy dispersive analysis: Applications in the field of cultural heritage. Anal Bioanal Chem 387:737-747.

Sotiropoulou S, Daniilia S, Miliani C, Rosi F, Cartechini L, Papanikola-Bakirtzis D. 2008. Microanalytical investigation of degradation issues in Byzantine wall paintings. Appl Phys A: Mater 92:143-150

Sendler E. 2001. L'icona immagine dell'invisibile. Roma: Paoline.

Taylor J. 1979. Icon Painting. Oxford: Phaidon. 